\title{
eMODIS: A User-Friendly Data Source
}

Open-File Report 2010-1055 



\section{eMODIS: A User-Friendly Data Source}

By Calli Jenkerson, Thomas Maiersperger, and Gail Schmidt

Open-File Report 2010-1055

U.S. Department of the Interior

U.S. Geological Survey 


\title{
U.S. Department of the Interior \\ KEN SALAZAR, Secretary \\ U.S. Geological Survey \\ Marcia K. McNutt, Director
}

\section{U.S. Geological Survey, Reston, Virginia: 2010}

\author{
For more information on the USGS — the Federal source for science about the Earth, its natural and living resources, \\ natural hazards, and the environment, visit http://www.usgs.gov or call 1-888-ASK-USGS \\ For an overview of USGS information products, including maps, imagery, and publications, \\ visit http://www.usgs.gov/pubprod \\ To order this and other USGS information products, visit http://store.usgs.gov
}

\begin{abstract}
Any use of trade, product, or firm names is for descriptive purposes only and does not imply endorsement by the U.S. Government.

Although this report is in the public domain, permission must be secured from the individual copyright owners to reproduce any copyrighted materials contained within this report.
\end{abstract}

Suggested citation:

Jenkerson, C.B., Maiersperger, Thomas, Schmidt, Gail, 2010, eMODIS: A user-friendly data source: U.S. Geological Survey Open-File Report 2010-1055, 10 p. 


\section{Acknowledgments}

eMODIS is made possible with funding from the U.S Geological Survey's Land Remote Sensing Program, Geographic Analysis and Monitoring Program, and Carbon Cycle Branch.

Support also is provided by the U.S. Department of Agriculture's National Agricultural Statistics Service. 



\section{Contents}

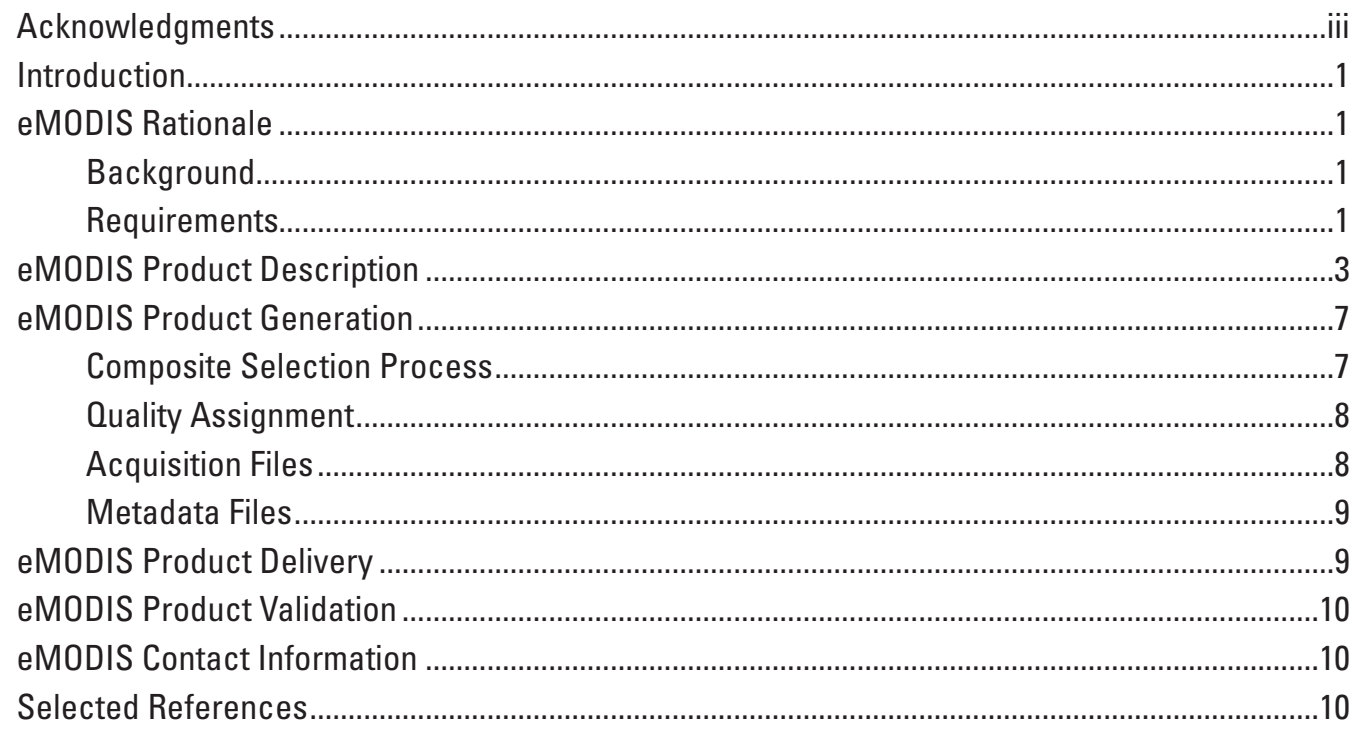

\section{Figures}

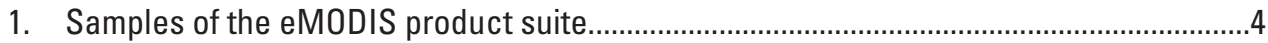

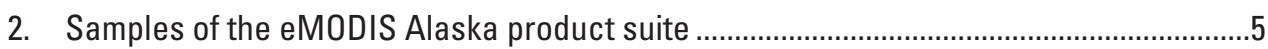

\section{Tables}

1. Specifications comparison between eMODIS and U.S. Geological Survey Earth Resources Observation Science Center Moderate Resolution Imaging Spectroradiometer Direct Broadcast System ..................................................................

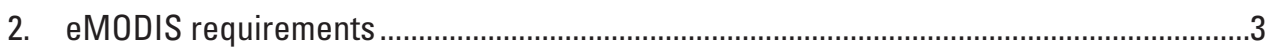

3. Seven-day composite image dimensions .....................................................................

4. Seven-day composite mapping grid parameters .............................................................

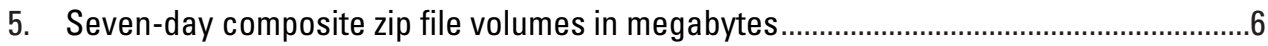

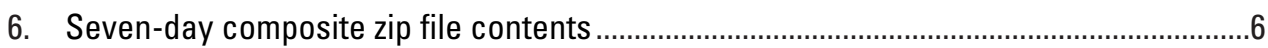

7. Seven-day composite output file volumes in megabytes .....................................................

8. Seven-day composite output file specifications .......................................................... 


\section{Conversion Factors and Datums}

Inch/Pound to International System of Units (SI)

\begin{tabular}{|c|c|c|}
\hline Multiply & By & To obtain \\
\hline \multicolumn{3}{|c|}{ Length } \\
\hline inch & 2.54 & centimeter $(\mathrm{cm})$ \\
\hline inch & 25.4 & millimeter (mm) \\
\hline foot $(\mathrm{ft})$ & 0.3048 & $\operatorname{meter}(\mathrm{m})$ \\
\hline mile (mi) & 1.609 & kilometer (km) \\
\hline mile, nautical (nmi) & 1.852 & kilometer (km) \\
\hline yard (yd) & 0.9144 & meter $(\mathrm{m})$ \\
\hline
\end{tabular}

Vertical coordinate information is referenced to the World Geodetic System 1984 (WGS 84).

Horizontal coordinate information is referenced to the World Geodetic System 1984 (WGS 84).

SI to Inch/Pound

\begin{tabular}{lcl}
\hline \multicolumn{1}{c}{ Multiply } & By & \multicolumn{1}{c}{ To obtain } \\
\hline & Length & \\
\hline centimeter $(\mathrm{cm})$ & 0.3937 & inch \\
millimeter $(\mathrm{mm})$ & 0.03937 & inch \\
meter $(\mathrm{m})$ & 3.281 & foot (ft) \\
kilometer $(\mathrm{km})$ & 0.6214 & mile (mi) \\
kilometer $(\mathrm{km})$ & 0.5400 & mile, nautical (nmi) \\
meter $(\mathrm{m})$ & 1.094 & yard (yd) \\
\hline
\end{tabular}

Vertical coordinate information is referenced to the World Geodetic System 1984 (WGS 84).

Horizontal coordinate information is referenced to the World Geodetic System 1984 (WGS 84). 


\section{Abbreviations and Acronyms}

\begin{tabular}{|c|c|}
\hline ASCII & American Standard Code for Information Interchange \\
\hline AVHRR & Advanced Very High Resolution Radiometer \\
\hline $\mathrm{CM}$ & Centimeter \\
\hline CONUS & Continental United States \\
\hline DBS & Direct Broadcast System \\
\hline DD & Decimal Degrees \\
\hline DOY & Day of Year \\
\hline EOS & Earth Observing System \\
\hline EROS & Earth Resources Observation and Science \\
\hline FOV & Field of View \\
\hline FT & Foot \\
\hline FTP & File Transfer Protocol \\
\hline GeoTIFF & Georeferenced Tagged Image File Format \\
\hline HDF-EOS & Hierarchical Data Format for EOS \\
\hline KB & Kilobyte \\
\hline KM & Kilometer \\
\hline LAADS & Level-1 and Atmospheres Archive and Distribution System \\
\hline LAEA & Lambert Azimuthal Equal Area \\
\hline M & Meter \\
\hline MB & Megabyte \\
\hline $\mathrm{Ml}$ & Mile \\
\hline MM & Millimeter \\
\hline MODAPS & MODIS Adaptive Processing System \\
\hline MODIS & Moderate Resolution Imaging Spectroradiometer \\
\hline MODLAND & MODIS Land Discipline Team \\
\hline MVC & Maximum Value Composite \\
\hline NA & Not Applicable \\
\hline NASA & National Aeronautics and Space Administration \\
\hline NDVI & Normalized Difference Vegetation Index \\
\hline NM & Nanometer \\
\hline NMI & Mile, Nautical \\
\hline NOAA & National Oceanic and Atmospheric Administration \\
\hline NRT & Near Real Time \\
\hline PGE & Product Generation Executable \\
\hline
\end{tabular}




$\begin{array}{ll}\text { OA } & \text { Quality Assessment } \\ \text { SI } & \text { International System of Units } \\ \text { USGS } & \text { U.S. Geological Survey } \\ \text { VI } & \text { Vegetation Index } \\ \text { WGS } & \text { World Geodetic System } \\ \text { YD } & \text { Yard }\end{array}$




\title{
eMODIS: A User-Friendly Data Source
}

\author{
By Calli Jenkerson, ${ }^{1}$ Thomas Maiersperger, ${ }^{2}$ and Gail Schmidt ${ }^{3}$
}

\section{Introduction}

The U.S. Geological Survey's (USGS) Earth Resources Observation and Science (EROS) Center is generating a suite of products called "eMODIS" based on Moderate Resolution Imaging Spectroradiometer (MODIS) data acquired by the National Aeronautics and Space Administration's (NASA) Earth Observing System (EOS). With a more frequent repeat cycle than Landsat and higher spatial resolutions than the Advanced Very High Resolution Spectroradiometer (AVHRR), MODIS is well suited for vegetation studies. For operational monitoring, however, the benefits of MODIS are counteracted by usability issues with the standard map projection, file format, composite interval, high-latitude "bow-tie" effects, and production latency. eMODIS responds to a community-specific need for alternatively packaged MODIS data, addressing each of these factors for real-time monitoring and historical trend analysis.

eMODIS processes calibrated radiance data (level-1B) acquired by the MODIS sensors on the EOS Terra and Aqua satellites by combining MODIS Land Science Collection 5 Atmospherically Corrected Surface Reflectance production code and USGS EROS MODIS Direct Broadcast System (DBS) software to create surface reflectance and Normalized Difference Vegetation Index (NDVI) products. eMODIS is produced over the continental United States and over Alaska extending into Canada to cover the Yukon River Basin. The 250-meter (m), 500-m, and 1,000-m products are delivered in Geostationary Earth Orbit Tagged Image File Format (GeoTIFF) and composited in 7-day intervals. eMODIS composites are projected to non-Sinusoidal mapping grids that best suit the geography in their areas of application (see eMODIS Product Description below).

For eMODIS products generated over the continental United States (eMODIS CONUS), the Terra (from 2000) and Aqua (from 2002) records are available and continue through

${ }^{1}$ ADNET Systems, Inc., contractor to the U.S. Geological Survey Earth Resources Observation and Science Center, Sioux Falls, S. Dak, work performed under contract 08HQCN0005.

${ }^{2}$ Stinger Ghaffarian Technologies (SGT), contractor to the U.S. Geological Survey Earth Resources Observation and Science Center, Sioux Falls, S. Dak., work performed under contract $08 \mathrm{HQCN} 0005$.

${ }^{3}$ Science Applications International Corporation (SAIC). present time. eMODIS CONUS also is generated in an expedited process that delivers a 7-day rolling composite, created daily with the most recent 7 days of acquisition, to users monitoring real-time vegetation conditions. eMODIS Alaska is not part of expedited processing, but does cover the Terra mission life (2000-present). A simple file transfer protocol (FTP) distribution site currently is enabled on the Internet for direct download of eMODIS products (ftp://emodisftp.cr.usgs. gov/eMODIS), with plans to expand into an interactive portal environment.

\section{eMODIS Rationale}

\section{Background}

NASA-EOS MODIS products provide NDVI and surface reflectance data with a more frequent overpass than Landsat and at higher spatial resolution than AVHRR. Vegetation monitoring studies benefit from these features, and the land science community has engaged MODIS data since its release in 2000 to enhance the accuracy of existing tools and to facilitate a link with the AVHRR record.

Despite the benefits of MODIS products, real-time applications were immediately challenged with making those products directly useful because of difficulties with reprojection, format conversion, mosaicking, and subsetting. Within the EROS science community, some users turned to the USGS EROS MODIS DBS to generate more user-friendly products and developed a reliance on them as input to their monitoring activities. When the USGS discontinued the EROS MODIS DBS in 2006, users pursued alternative data sources and solicited the USGS Land Remote Sensing Program for a prototype eMODIS system. "eMODIS" thus represents "enhanced," "expedited," and "expandable" MODIS data from EROS.

\section{Requirements}

The initial production design for eMODIS was based on prototyping a replacement for the EROS MODIS DBS. Table 1 outlines the conceptualized similarities and differences between eMODIS and its parent DBS specifications. 
Table 1. Specifications comparison between eMODIS and U.S. Geological Survey Earth Resources Observation and Science Center Moderate Resolution Imaging Spectroradiometer Direct Broadcast System.

[MODIS, Moderate Resolution Imaging Spectroradiometer; EROS, Earth Resources Observation and Science; DBS, Direct Broadcast System; NOAA, National Oceanic and Atmospheric Administration; NRT, Near Real Time; GDAS_OZF, Global Data Assimilation System Ozone; OZONEEP, Total Ozone Mapping Spectrometer Column Ozone Earth Probe; NISE, National Snow and Ice Data Center, Near Real Time Global Ice and Snow Extent; SEA_ICE, National Centers for Environmental Prediction Ice Concentration; REYNSST, Reynolds Weekly Sea Surface Temperature from National Oceanic and Atmospheric Administration, National Centers for Environmental Prediction; GBLAV, Global Operational Aviation Analyses and Forecasts; avn_ozone, Aviation Run Total Ozone; PGE, Product Generation Executable; NDVI, Normalized Difference Vegetation Index; CONUS, Continental United States; , approximately; LAEA/GeoTIFF, Lambert Azimuthal Equal Area/Geostationary Earth Orbit Tagged Image File Format]

\begin{tabular}{lll}
\hline & \multicolumn{1}{c}{ eMODIS } & \multicolumn{1}{c}{$\begin{array}{c}\text { EROS Center MODIS DBS } \\
\text { (end April 2006) }\end{array}$} \\
\hline Data source & NOAA NRT system & EROS antennae \\
Instruments & Terra and Aqua MODIS & Terra and Aqua MODIS \\
Ingested processing level & Level 1B Swath & Level 0 Swath \\
Ancillary inputs & GDAS_OZF (OZONEEP), NISE, SEA_ICE, & GBLAV, avn_ozone, NISE, SEA_ICE \\
& REYNSST & \\
Algorithms & Collection 5 MODIS PGE 03, PGE 11 & Collection 4 MODIS PGE 03, PGE 11 \\
Output layers & NDVI, Surface Reflectance Bands, Quality, & NDVI, Surface Reflectance Bands, \\
& Acquisition Date & Quality, Acquisition Date \\
Geographic extent & CONUS & CONUS \\
Product latency & $\sim 1$ day after last input & $\sim 1$ day after last input \\
Composite schedule & Daily rolling 7-day & Daily rolling 7-day \\
Output projection/format & LAEA/GeoTIFF & LAEA/GeoTIFF \\
Archive capability & Yes & No \\
Historic reprocessing capability & Yes & No
\end{tabular}

The USGS collaborated with the NASA EOS Project to complete a prototype eMODIS system. In December 2007, a system was in place to accomplish the following:

- Ingest real-time MODIS L1B data over continental United States from National Oceanic and Atmospheric Administration's (NOAA) Near Real Time (NRT) system.

- Archive ancillary and intermediate products needed for processing expedited data.

- Use the latest (May 2007) Collection 5 Product Generation Executable (PGE) 11 code and recycled EROS MODIS DBS code to process L1B files into surface reflectance and NDVI composites.

- Provide expedited 7-day rolling composites over continental United States at 250-m, 500-m, and 1,000-m resolutions, Lambert Azimuthal Equal Area (LAEA) projection, GeoTIFF format.

- Distribute from a nominal 30-day archive hosted from a direct FTP access Internet site.
Data validation was included in the prototype activity to verify the general consistency of processing artifacts, geolocation, data quality, and data accuracy. The evaluation is summarized in the unpublished eMODIS "readme" file distributed from the FTP site and describes satisfactory production output (ftp://emodisftp.cr.usgs.gov/eMODIS/ CONUS/).

The success of the prototype effort prompted the addition of historical production to the eMODIS system. Enhancements for historical production include the use of a definitive source for precision L1B inputs, the use of EROS AVHRR weeks to describe a 7-day interval (http:// ivm.cr.usgs.gov/links.php), and permanent retention of the products. Both expedited and historical processing have been supported over the continental United States since January 2008, and coverage over Alaska (including that portion of the Yukon River Basin extending into Canada) was added later that year. The core product requirements are listed in table 2. Because eMODIS is designed as an extensible system, augmentations satisfying future temporal, geographic, or geophysical requirements will be easily integrated. 
Table 2. eMODIS requirements.

[CONUS, Continental United States; , approximately; <, less than; MODIS, Moderate Resolution Imaging Spectroradiometer; LAEA/GeoTIFF, Lambert Azimuthal Equal Area/ Geostationary Earth Orbit Tagged Image File Format; m, meter; NDVI, Normalized Difference Vegetation Index; Advanced Very High Resolution Radiometer; AVHRR]

\begin{tabular}{|c|c|c|c|}
\hline & Expedited & Historical CONUS & Historical Alaska \\
\hline Timeliness & $\sim 1$ day after last input & $<30$ days after last input & $<30$ days after last input \\
\hline Temporal extent & Current week & $2000-$ present & $\begin{array}{l}\text { February - October } \\
2000 \text { - present }\end{array}$ \\
\hline Instruments & MODIS & Terra and Aqua MODIS & Terra MODIS \\
\hline Geographic extent & CONUS & CONUS & $\begin{array}{l}\text { Alaska including Yukon River Basin, } \\
\text { excluding Aleutian Islands }\end{array}$ \\
\hline Projection/Format & LAEA/GeoTIFF & LAEA/GeoTIFF & Alaska Albers Equal Area/GeoTIFF \\
\hline Spatial resolution & $250-\mathrm{m}, 500-\mathrm{m}, 1,000-\mathrm{m}$ & $250-\mathrm{m}, 500-\mathrm{m}, 1,000-\mathrm{m}$ & 250-m, 500-m, 1,000-m \\
\hline Layers & $\begin{array}{l}\text { NDVI, Surface Reflectance Bands, } \\
\text { Quality, Date }\end{array}$ & $\begin{array}{l}\text { NDVI, Surface Reflectance } \\
\text { Bands, Quality, Date }\end{array}$ & $\begin{array}{l}\text { NDVI, Surface Reflectance Bands, } \\
\text { Quality, Date }\end{array}$ \\
\hline Composite period & 7-day rolling & $\begin{array}{l}\text { 7-day interval according to } \\
\text { AVHRR calendar }\end{array}$ & 7-day interval starting January 1 \\
\hline Archive persistence & 30 days & Long term & Long term \\
\hline
\end{tabular}

\section{eMODIS Product Description}

The eMODIS suite of products includes eMODIS CONUS and eMODIS Alaska. eMODIS enhancements for both include distribution of 7-day composites as GeoTIFFs, rejection of pixels on the east and west edges of a swath to mitigate the "bow-tie" effect, and use of a snow filter to tag snowy pixels when no other pixels are available. Each dataset includes reflectance, acquisition, quality, and NDVI information at $250-\mathrm{m}, 500-\mathrm{m}$, and $1,000-\mathrm{m}$ spatial resolutions.

The historically produced data over the continental United States are composited within a 7-day interval matching the historical EROS AVHRR compositing scheme. Expedited production runs daily, using the last 7 days of acquisitions as input to the composites. The products, generated independently for both Terra and Aqua MODIS, are projected to a LAEA sphere. Figure 1 shows examples of the eMODIS CONUS product.

eMODIS Alaska products are composited over 7-day weeks, defined from January 1, but are produced only during the growing season (February-October). There is no expedited production in Alaska. The composites represent the entire geographic region on the Alaska Albers Equal Area mapping grid and are produced only for Terra. An additional enhancement specific to eMODIS Alaska is the implementation of a sun angle threshold $\left(83^{\circ}\right)$. Figure 2 shows examples of the eMODIS Alaska product.
Both eMODIS CONUS and eMODIS Alaska distribute the following files:

- NDVI (band 2 - band $1 /$ band $2+$ band 1 )

- Atmospherically corrected surface reflectance

- Band 1 (620-670 nanometer $(\mathrm{nm}))$ red

- Band 2 (841-876 nm) near infrared

- Band 3 (459-479 nm)

- Band 4 (545-565 nm)

- Band $5(1,230-1,250 \mathrm{~nm})$

- Band $6(1,628-1,652 \mathrm{~nm})$

- Band 7 (2,105-2,155 nm)

- Quality of reflectance and NDVI

- Day of acquisition

- Metadata

Native spatial resolution for the reflectance bands is 250-m in bands 1 and 2 and 500-m in bands 3-7. All bands are aggregated accordingly for the eMODIS 500-m and 1,000-m products; that is, bands 1 and 2 are resampled to $500-\mathrm{m}$ in the $500-\mathrm{m}$ product, and all bands are resampled to $1,000-\mathrm{m}$ in 

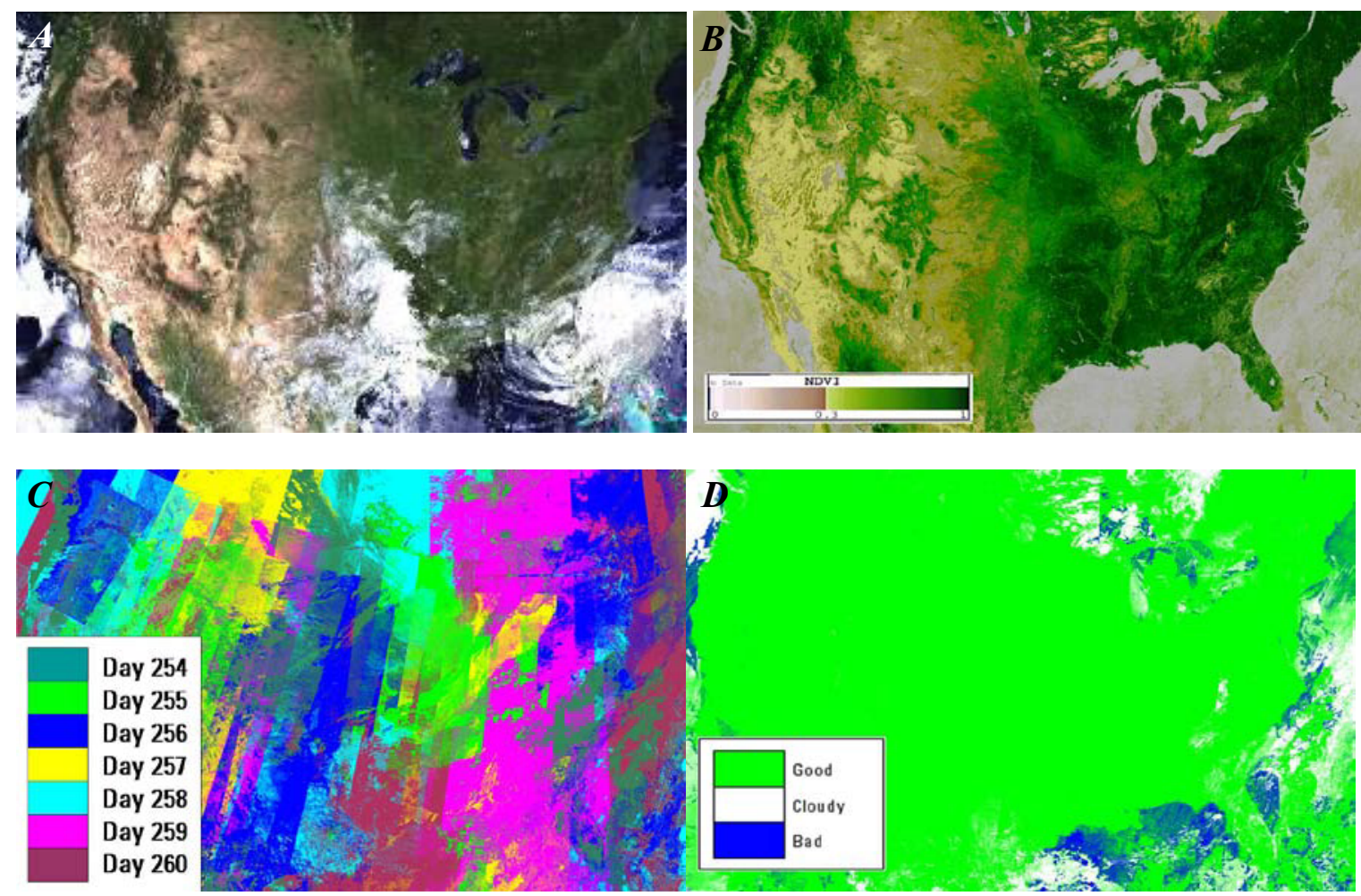

Figure 1. Samples of the eMODIS product suite. A, RGB image created with Bands 1, 4, and 3 from 500 -meter data acquired August 15-21, 2008, showing Hurricane Fay moving into the southeast United States. $B$, Falsecolored 250-meter Normalized Difference Vegetation Index calculated with data from September 11-17, 2007. $C$, Corresponding images for the same interval in 2007 depicting per-pixel day of acquisition. $D$, Corresponding images for the same interval in 2007 depicting per-pixel quality.

the $1,000-\mathrm{m}$ product. The $250-\mathrm{m}$ product, however, includes only bands 1 and 2 as original 250 -m pixels. Table 3 contains the image dimensions for each product, and the geographic dimensions of the composites are defined in table 4 with the output map projection parameters for CONUS and Alaska respectively. Center of pixel is exclusive to spatial resolution, so coordinates may vary slightly between the $250-\mathrm{m}, 500-\mathrm{m}$, and 1,000-m lower right corners.

In contrast to the NASA-EOS MODIS Vegetation Indices (VI) that layer VI, reflectance, and quality information in a single Hierarchical Data Format for Earth Observing Systems (HDF-EOS) file, eMODIS provides separate GeoTIFF files for each product in a 7-day interval, allowing the users to download only the files they need. The NDVI and every reflectance band have five associated files: data, quality, metadata, acquisitions image, and an acquisitions table (see eMODIS Product Generation, Acquisition Files below). Consequently, 45 files can be expected per 500-m and 1,000-m data set whereas the $250-\mathrm{m}$ product will have only 20 . All associated files (GeoTIFFs, ".met," and ".txt") are packaged into a ".zip" file which is coupled with a checksum (".sum.") for distribution. There is one zip file and one checksum for NDVI and a separate zip and checksum for reflectance. The average volume for each zip is shown in table 5 .

A typical dataset includes the products listed below compressed into two zip files, the contents of which are stated in table 6. File volumes and further specifications are detailed in tables 7 and 8.

The NDVI data are specified with a valid range "-1,999 - 10,000." The value “- 1,999 " is assigned to any VI computation between "-1,998" and "-10,000." VI computations between "-1" and "-1,997" are assigned face value. When surface reflectance input pixels contain negative or fill values, the pixel will have a “-2,000” for NDVI and a corresponding " 10 " in the band quality layer.
[MODIS, Moderate Resolution Imaging Spectroradiometer; CONUS, Continental United States; m, meter]

\begin{tabular}{lcccc}
\hline Product & $\begin{array}{c}\text { eMODIS CONUS X } \\
\text { (samples) }\end{array}$ & $\begin{array}{c}\text { eMODIS CONUS Y } \\
\text { (lines) }\end{array}$ & $\begin{array}{c}\text { eMODIS Alaska X } \\
\text { (samples) }\end{array}$ & $\begin{array}{c}\text { eMODIS Alaska Y } \\
\text { (lines) }\end{array}$ \\
\hline $250-\mathrm{m}$ & 18,348 & 11,556 & 9,322 & 7,064 \\
$500-\mathrm{m}$ & 9,174 & 5,778 & 4,661 & 3,532 \\
$1,000-\mathrm{m}$ & 4,587 & 2,889 & 2,330 & 1,766 \\
\hline
\end{tabular}



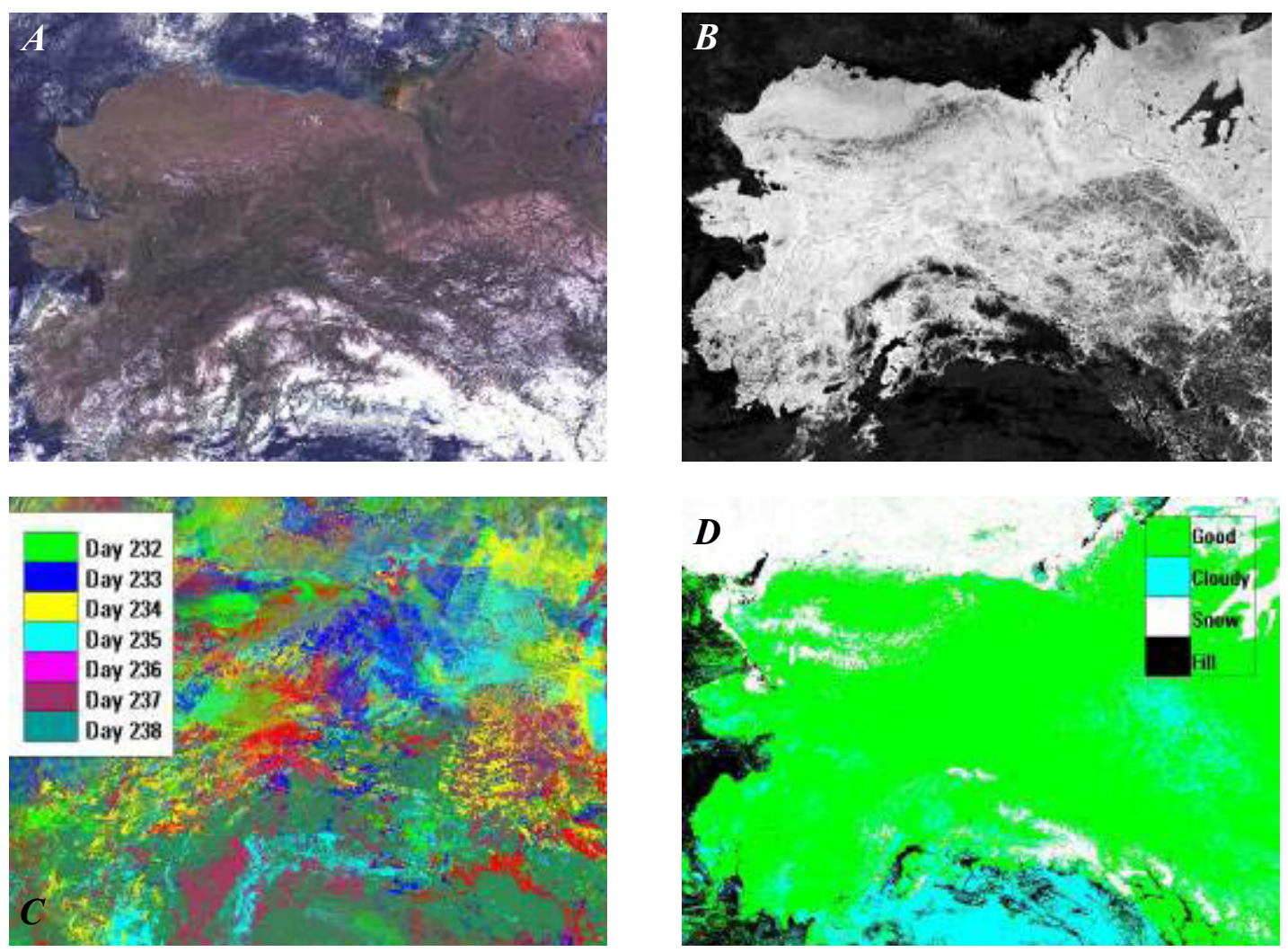

Figure 2. Samples of the eMODIS Alaska product suite. $A, \mathrm{RGB}$ image created with Bands 1,4 , and 3 from 500-meter data acquired from August 20-26, 2007. B, Grey-scaled 250-meter Normalized Difference Vegetation Index calculated with data from the same interval. $C$, Corresponding images for the same interval depicting per-pixel day of acquisition. $D$, An example from June 11-17, 2003, depicting per-pixel quality.

Table 4. Seven-day composite mapping grid parameters.

[MODIS, Moderate Resolution Imaging Spectroradiometer; CONUS, Continental United States; LAEA, Lambert Azimuthal Equal Area; WGS, World Geodetic System; DD, Decimal Degrees; NA, not applicable; Lat, latitude; Lon, longitude]

\begin{tabular}{lcc}
\hline & eMODIS CONUS & eMODIS Alaska \\
\hline Projection & LAEA & Alaska Albers Equal Area \\
Sphere/Datum & 6370997.00 (Sphere 19) & WGS 84 \\
Central Longitude/Meridian DD & -100.00 & -154.0000000 \\
Central Latitude/Latitude of Origin DD & 45.00 & 50.0000000 \\
Standard Parallel 1 DD & NA & 55.0000000 \\
Standard Parallel 2 DD & NA & 65.0000000 \\
Semimajor Axis & NA & 6378137 \\
Semiminor Axis & NA & 6356752.31 \\
*Upper Left Lat,Lon DD (center of pixel) & $48.4030555,-128.5300591$ & $72.0000000,-173.0000000$ \\
*Lower Right Lat,Lon DD (center of pixel) & $22.4793919,-75.4163527$ & $54.0029556,-128.9981667$ \\
*Upper Left Output X,Y (center of pixel) & $-2050500,752500$ & $2538877.50,-666333.75$ \\
*Lower Right Output X,Y (center of pixel) & $2536500,-2136500$ & $773127.50,1663916.25$ \\
\hline
\end{tabular}

${ }^{*}$ Coordinates apply to 500-meter and 1,000-meter composites. Because of center of pixel designation, 250-meter coordinates will vary slightly from these reported. 
Table 5. Seven-day composite zip file volumes in megabytes.

[CONUS, Continental United States; NDVI, Normalized Difference Vegetation Index; $\mathrm{MB}$, megabyte; $\mathrm{m}$, meter]

\begin{tabular}{|c|c|c|c|c|}
\hline Product & $\begin{array}{c}\text { eMODIS CONUS } \\
\text { NDVI } \\
\text { ZIP } \\
\text { (MB) }\end{array}$ & $\begin{array}{c}\text { eMODIS CONUS } \\
\text { REFLECTANCE } \\
\text { ZIP } \\
\text { (MB) }\end{array}$ & $\begin{array}{l}\text { eMODIS Alaska } \\
\text { NDVI } \\
\text { ZIP } \\
\text { (MB) }\end{array}$ & $\begin{array}{c}\text { eMODIS Alaska } \\
\text { REFLECTANCE } \\
\text { ZIP } \\
\text { (MB) }\end{array}$ \\
\hline 250-m & 352.9 & 715.6 & 112.4 & 237.1 \\
\hline $500-\mathrm{m}$ & 89.7 & 634.6 & 28.9 & 211.1 \\
\hline $1,000-\mathrm{m}$ & 22.9 & 161.9 & 6.6 & 53.9 \\
\hline
\end{tabular}

Table 6. Seven-day composite zip file contents.

[m, meter; NDVI, Normalized Difference Vegetation Index]

\begin{tabular}{|c|c|}
\hline Filename & Description \\
\hline \multicolumn{2}{|c|}{ composite500m_AQUA_NDVI_2005_7.zip } \\
\hline 500m_composite_ndvi.tif & NDVI data \\
\hline 500m_composite_ndvi_bq.tif & NDVI data quality \\
\hline 500m_composite_ndvi.met & NDVI data metadata \\
\hline 500m_composite_ndvi_acq.tif & NDVI data acquisitions image \\
\hline 500m_composite_ndvi_acq_table.txt & NDVI data acquisitions table \\
\hline \multicolumn{2}{|c|}{ composite500m_AQUA_REFL_2005_7.zip } \\
\hline 500m_composite_b*.tif & reflectance data \\
\hline 500m_composite_b*_bq.tif & reflectance data quality \\
\hline 500m_composite_b*.met & reflectance data metadata \\
\hline 500m_composite_b*_acq.tif & reflectance data acquisitions image \\
\hline 500m_composite_b*_acq_table.txt & reflectance data acquisitions table \\
\hline *Repeated per band (1-7) & all of the above \\
\hline
\end{tabular}

Table 7. Seven-day composite output file volumes in megabytes.

[m, meter; MB, megabyte; CONUS, Continental United States; NDVI, Normalized Difference Vegetation Index; KB, kilobyte]

\begin{tabular}{|c|c|c|c|c|c|c|}
\hline \multirow{2}{*}{ File } & \multicolumn{2}{|c|}{ 250-m Average (MB) } & \multicolumn{2}{|c|}{ 500-m Average (MB) } & \multicolumn{2}{|c|}{ 1,000-m Average (MB) } \\
\hline & eMODIS CONUS & eMODIS Alaska & eMODIS CONUS & eMODIS Alaska & eMODIS CONUS & eMODIS Alaska \\
\hline $\begin{array}{l}\text { Reflectance bands } \\
\quad 1-7\end{array}$ & 405 & 126 & 101 & 32 & 25 & 8 \\
\hline NDVI & 405 & 126 & 101 & 32 & 25 & 8 \\
\hline Quality & 202 & 63 & 51 & 16 & 13 & 4 \\
\hline Acquisitions image & 405 & 126 & 101 & 32 & 25 & 8 \\
\hline Acquisitions table & .004 & .02 & .004 & .02 & .004 & .02 \\
\hline Metadata & .003 & $3 \mathrm{~KB}$ & .003 & $3 \mathrm{~KB}$ & .003 & $3 \mathrm{~KB}$ \\
\hline
\end{tabular}


Table 8. Seven-day composite output file specifications.

[NDVI, Normalized Difference Vegetation Index; NA, not applicable; ASCII, American Standard Code for Information Interchange]

\begin{tabular}{llccc}
\hline \multicolumn{1}{c}{ File } & \multicolumn{1}{c}{ Data type } & Valid range & Fill value & Scale factor \\
\hline Reflectance bands 1-7 & 16-bit signed integer & $-100-16,000$ & $-28,672$ & 0.0001 \\
NDVI & 16-bit signed integer & $-1,999-10,000$ & $-2,000$ & .0001 \\
Quality & 8-bit unsigned integer & $0-$ good & NA \\
& & $1-$ cloudy & 10 & \\
& & 2- bad band quality & & \\
& & - negative reflectance & & \\
Acquisitions image & 16-bit unsigned integer & $10-$ fill & & NA \\
Acquisitions table & Delimited text & $101-36699$ & NA & NA \\
Metadata & ASCII & $101-36699$ & NA & NA \\
\hline
\end{tabular}

\section{eMODIS Product Generation}

The eMODIS 7-day composites are produced with a combination of the software used to create standard NASA-EOS MODIS products and software from the former EROS MODIS DBS. Collection 5 MODIS code acquired from MODIS Adaptive Processing System (MODAPS) Services Software Distribution (http://modaps.nascom.nasa.gov:9500/) is implemented as the eMODIS "house" algorithm. It is used to generate atmospherically corrected level-2 surface reflectance swaths, from which USGS EROS MODIS DBS software processes the final composites. The input level-1B data are downloaded from the Level 1 and Atmosphere Archive and Distribution System (LAADS) into historical processing, whereas expedited production uses data from the NOAA NRT system.

The compositing process begins with all level-2 surface reflectance swaths relevant to the CONUS or Alaska extent. The first step strips the outer 150,000-m of data from the east and west borders of the level-2 surface reflectance data in order to remove the pixels located at a distance from nadir that is likely to cause a "bow-tie effect." Next, the algorithm grids the needed swath products (stripped surface reflectance, geolocation, and cloud mask) within the mapping coordinates listed in table 4.

A simple NDVI calculation achieved by using band 1 (red) and band 2 (near infrared) is then made for each gridded surface reflectance file. The resulting gridded NDVI files, representing all available coverage, are fed into an enhanced maximum value composite (MVC) algorithm. A traditional MVC would be populated by using the highest NDVI chosen from all available values for a pixel in the 7-day period. For the eMODIS composites, the MVC algorithm is modified to incorporate band quality, negative surface reflectance, cloud mask, snow cover, view angle, and for Alaska, sun angle, as described in the section on Composite Selection Process.
The MVC outputs finally are stitched together by an EROS MODIS DBS compositing process to create the eMODIS 7-day NDVI composites. The surface reflectance and acquisitions composites are put together by using the pixels selected as MVC input.

\section{Composite Selection Process}

The pixels populating the final eMODIS product are selected through an enhanced MVC algorithm by using a fivestep (CONUS) or six-step (Alaska) process to filter through input surface reflectance with bad quality, negative values, clouds, snow cover, low view angles, or low sun angles (Alaska).

1. The band quality information in the level-2 surface reflectance data are used to determine if a certain pixel is of "bad quality." The standard MODIS Land Science Team (MODLAND) Quality Assessment (QA) bits are carried into the production of the 250$\mathrm{m}, 500-\mathrm{m}$, and 1,000-m surface reflectance data. Bad or less than ideal quality surface reflectance pixels are not used in eMODIS production, leaving pixels with QA values of " 00 " as the only input candidates.

MODLAND QA bits 0-1

corrected product produced at

00 - ideal quality all bands

01 - less than ideal quality some or all bands

corrected product not produced due to

10 - cloud effects all bands

11 - other reasons some or all bands may be fill value. [Note that a value of (11) overrides a value of (01)] 
2. Pixels with negative surface reflectance values are immediately flagged to exclude them as potential input to the gridded NDVI files, unless there are no positive values available. In the rare case that a negative surface reflectance value is retained, the resulting gridded NDVI value is flagged as "- 3,000 " so that the pixel for that day in the period will be ignored in the MVC process.

3. CONUS processing continues with the next step, but at this point, eMODIS Alaska extracts the solar zenith angle from the 1,000-m geolocation product and resamples it for the $250-\mathrm{m}$ and $500-\mathrm{m}$ products. Any pixels acquired at sun angles greater than $83^{\circ}$ are eliminated as composite candidates.

4. The level-2 cloud mask product is used to minimize the overall presence of cloudy pixels in the production stream. Data from the first byte (band) in the cloud mask are used for cloud assessment. If bit 0 (see below) is "not determined," then the associated pixel is treated as cloudy. If bit 0 is "determined" and bits 1-2 indicate a "cloudy" pixel, the pixel is excluded unless there are no suitable pixels available in the 7-day record and data for the pixel were from the most recent acquisition (see Quality Assignment)

If bit 0 is "determined" and bits 1-2 indicate "probably clear" or "confident clear," then the corresponding surface reflectance pixel is eligible in the MVC process. The following bit interepretation legend includes information on the field of view (FOV).

\begin{tabular}{cll} 
Bit field & \multicolumn{1}{c}{ Description } & \multicolumn{1}{c}{ Key } \\
0 & Cloud Mask Flag & $0=$ Not determined \\
& & $1=$ Determined \\
$2,1 \quad$ Unobstructed FOV Quality Flag & $00=$ Cloudy \\
& $01=$ Uncertain \\
& $10=$ Probably Clear \\
& $11=$ Confident Clear
\end{tabular}

5. At this point in the filtering process, the two highest NDVI values in the remaining ideal-quality, nonnegative, noncloudy pixels are checked for snow cover, which is read from the first byte in the level-2 cloud mask product.

\begin{tabular}{ccl} 
Bit field & \multicolumn{1}{c}{ Description } & \multicolumn{1}{c}{ Key } \\
5 & Snow Flag & $0=$ Snow $/$ Ice \\
& & $1=$ No Snow/Ice
\end{tabular}

If one of the two highest NDVI values is flagged as snowy, it is eliminated from the selection process, and the single remaining pixel is used in the final composite. If neither or both values are snowy, the pixels are finally examined for their position from nadir.
6. The view angle (distance from nadir) finally determines which gridded NDVI pixel is used in the composite. The sensor zenith angle taken from the $1,000-\mathrm{m}$ geolocation product is used to determine the view angle and is resampled for the $250-\mathrm{m}$ and $500-\mathrm{m}$ products. The two highest NDVI values in the remaining ideal-quality, nonnegative, noncloudy, nonsnowy pixels are assessed for their position from nadir by using the geolocation information. Whichever of these two pixels is closest to nadir will be used to populate the final composite.

NOTE: It is possible for off-nadir pixels to be selected for the composite since in some cases the off-nadir pixels may have a higher NDVI than those closer to nadir.

The composite resulting from the MVC process is then stitched inside CONUS or Alaska space to provide the eMODIS 7-day composites.

\section{Quality Assignment}

A quality file is produced by the eMODIS software to track each pixel in the composite. The highest quality pixels are filtered through the Composite Selection Process, but there can be situations when no good quality surface reflectance values were acquired for a particular pixel. The best available pixel is always preferred for the final composite but in cases when the "best" is snowy, cloudy, or negative, the accompanying QA product will describe its condition. In the worst case, in which all available pixels have negative surface reflectance, are cloudy, snow-covered, and at unacceptable view or sun angles, MVC will use the most recently acquired pixel that does not carry an original fill value $(-28,672)$.

The following values are used in the QA band:

$$
\begin{aligned}
& 0=\text { good quality } \\
& 1=\text { cloudy pixel } \\
& 2=\text { bad band quality } \\
& 3=\text { negative surface reflectance } \\
& 4=\text { snow } \\
& 10=\text { fill }
\end{aligned}
$$

\section{Acquisition Files}

Because the composites are created from up to 56 files for CONUS and well over 100 files for Alaska, the eMODIS products include acquisitions files to identify which of the possible inputs were used to populate the final composite. As stated in the section on eMODIS Product Characteristics, there is a composite image of dates (acq.tif), as well as an American Standard Code for Information Interchange (ASCII) file (acq. txt), listing the dates for each pixel. The acquisitions image and acquisitions table contain the same information in different formats. The original acquisition used in the composite production is identified in an integer formatted as "DOY AQ." 
Day of year is "DOY," and "AQ" is the acquisition number, which in this case represents the order of capture rather than the time of acquisition and is one-based. For example, an acquisitions value of "11702" identifies the second capture (02) from April 27 (117) as the input selected for the composite. Likewise, an acquisition value of "1001" represents day 10 (January 10), first capture.

\section{Metadata Files}

The metadata accompanying the data files summarize geographic bounds, projection parameters, and product contact information.

\section{eMODIS Product Delivery}

eMODIS NDVI and reflectance zip files are delivered immediately after production to a direct access FTP site, along with calculated checksum files for each zip. Users navigate a simple directory tree to download eMODIS output.

ftp://emodisftp.cr.usgs.gov/eMODIS

$<$ extent $>$ /

$<$ productionstream $>1$

$<$ SENSOR $>$ /

$<$ year $>$ /

comp_<endday $>$ /

composite $<$ resolution $>\mathrm{m}_{-}<$SENSOR $>$NNDVI_ $<$year $>$_ $<$endday $>$.zip

composite $<$ resolution $>\mathrm{m}_{-}<$SENSOR $>$REFL_ $<$year $>$_ $<$endday $>$.zip

where $<$ extent $>$ is "CONUS" or "Alaska"

$<$ productionstream $>$ is "expedited" or "historical"

$<$ SENSOR $>\quad$ is "AQUA" or "TERRA"

$<$ year $>\quad$ is acquisition year, e.g., 2005

$<$ endday $>\quad$ is the Julian date for the last day of a 7-day interval

$<$ resolution $>\quad$ is " 250 ," " 500 ," or " 1000 "

For example, ftp://emodisftp.cr.usgs.gov/eMODIS/CONUS/expedited/TERRA/2008/ comp_249/

09/05/2008 06:31PM 23,300,786_composite1000m_TERRA_NDVI_2008_249.zip

09/05/2008 06:31PM 159,691,723 composite1000m_TERRA_REFL_2008_249.zip

09/06/2008 12:40AM 360,246,011 composite250m_TERRA_NDVI_2008_249.zip

09/06/2008 12:38AM 709,872,934 composite250m_TERRA_REFL_2008_249.zip

09/05/2008 08:41PM 91,472,635 composite500m_TERRA_NDVI_2008_249.zip

09/05/2008 08:40PM 629,760,762 composite500m_TERRA_REFL_2008_249.zip

In the expedited production stream, the output zip files are delivered within 24 hours of the last input acquisition. Note in the directory listing above that the files for the 7-day interval ending on Julian day 2008249 (September 5, 2008) completed production by 12:40AM the next day (September 6).

Production in the historical stream generally is well within 30 days of the last input acquisition for current data and is dependent on the availability of well-defined ancillary data, including spacecraft location and climatology. Historical production for the Terra mission has been completed over the continental United States and Alaska from February 2000 to the present, and for the Aqua mission, over the continental United States from July 2002 to the present. Production continues with the current MODIS record.

The eMODIS FTP site provides very basic access to the product suite. The user community has requirements to enhance this delivery vehicle in order to maximize the applications-ready appeal of the products. Development is underway to provide an attractive and intuitive Web interface through which interactive services will be used to visualize, subset, and reformat eMODIS data if desired. This capability will add flexibility to the eMODIS products, expanding their relevance in the user community. 


\section{eMODIS Product Validation}

A full scale validation of eMODIS was planned in 2009, with subsequent publications expected. A general characterization of data consistency in terms of processing artifacts, geolocation, data quality, and data accuracy accompanies the "readme" documents on the eMODIS FTP site (ftp:// emodisftp.cr.usgs.gov/eMODIS). Requests for further information and publication references may be directed to the author (see eMODIS Contact Information).

\section{eMODIS Contact Information}

Calli Jenkerson

jenkerson@usgs.gov

(605) 594-2638

\section{Selected References}

Alvord, C., Brown, J.F., Jenkerson, C.B., and Gu, Y., 2008, Vegetation health (crops, rangeland, forest) products-NIDIS Remote Sensing Workshop, showcase of products \& technologies: Intermountain West Climate Summary, v. 4, no. 4, p. 5-6, accessed May 19, 2008, at http://wwa.colorado.edu/ IWCS/archives.html.
Brown, J.F., Jenkerson, C.B., and Gu, Y., 2008, Using eMODIS vegetation indices for operational drought monitoring [abs.], in Contributions of satellite remote sensing to drought monitoring, National Integrated Drought Information System Knowledge Assessment Workshop, Boulder, Colo., Feb. 6-8, 2008, Extended Abstracts: U.S. Geological Survey and the Western Water Assessment. (Also available online at $h t t p: / / w w w . d r o u g h t . g o v / p o r t a l / s e r v e r . p t / 4$ community/drought_gov/202/remote_sensing_workshop_-_ abstracts).

Jenkerson, C.B., 2009, eMODIS overview [abs.], in Reflection of the past, vision for the future, Annual Conference, Baltimore, Md., Mar. 9-13, 2009, Proceedings: Bethesda, Md., American Society for Photogrammetry and Remote Sensing, unpaged CD-ROM.

Jenkerson, C.B., and Schmidt, G., 2009, eMODIS Alaska, in Reflection of the past, vision for the future, Annual Conference, Baltimore, Md., Mar. 9-13, 2009, Proceedings: Bethesda, Md., American Society for Photogrammetry and Remote Sensing, unpaged CD-ROM.

Jenkerson, C.B., and Schmidt, G., 2008, eMODIS product access for large scale monitoring, in The future of land imaging ... going operational, William T. Pecora Memorial Symposium on Remote Sensing, 17th, Denver, Colo., Nov. 16-20, 2008, Proceedings: Bethesda, Md., American Society for Photogrammetry and Remote Sensing, p. 19. 
Publishing support provided by:

Rolla Publishing Service Center

For more information concerning this publication, contact:

U.S. Geological Survey Earth Resources Observation and Science (EROS) Center

Sioux Falls, South Dakota

(605) 594-6151

Or visit the EROS Center Web site at:

World Wide Web: http://eros.usgs.gov/ 
กี๊ 